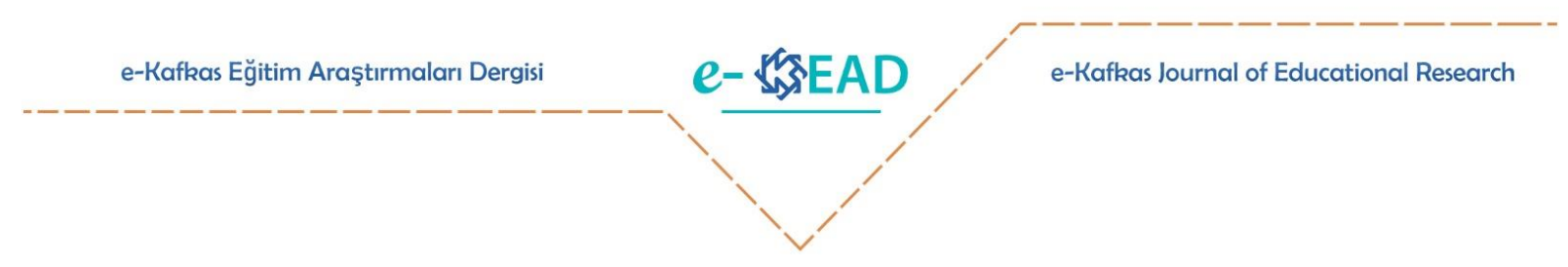

\title{
Ortaokul Öğrencilerinin Matematik Ders Başarılarının Ebeveyn Desteği Açısından İncelenmesi *
}

\author{
Zekiye Morkoyunlu (1D $\triangle$ Alper Cihan Konyalıŏlu
}

Atıf: Morkoyunlu, Z. ve Konyalığlu, A. C. (2020). Ortaokul öğrencilerinin matematik ders başarılarının ebeveyn desteği açısından incelenmesi. e- Kafkas Ĕ̈itim Araştırmaları Dergisi, 7, 16-27. doi:10.30900/kafkasegt.680563

Araştırma Makalesi

Geliş Tarihi: 27.01.2020

Kabul Tarihi: 06.03.2020

\section{$\ddot{O} z$}

Ebeveyn desteğinin genel olarak eğitimde etkili olduğu kadar özelde de matematik eğitiminde göz önünde bulundurulması gereken bir konu olduğu artık araştırmalarca desteklenmektedir. Ancak bu desteğin nasıl olması gerektiği konusunda sınırlı sayıda araştırma mevcuttur. Araştırmalar genelde korelasyonel çalışmalar olup uygulamaya dönük az sayıda çalışmaya rastlanılmıştır. Bu bakımdan bu çalışmada uygulama destekli akademik başarı incelemek istenmiştir. Bu doğrultuda çalışmanın amacı, ebeveyn desteğinin ortaokul öğrencilerinin matematik ders başarısına ne derece etki ettiğini belirlemeye çalışmaktır. Bu amaca yönelik olarak çalışmaya, ortaokul 6. sınıfta çocukları olan ebeveynler ve bu ebeveynlerin çocukları ile bu çocuklarla eş değer öğrenim gören benzer sayıda sınıf arkadaşları çalışmaya seçilmiştir. Çalışmanın örneklemi gönüllülük esaslı belirlenmiştir. Çalışmaya dair uygulama iki dönemde yedi hafta boyunca gerçekleştirilmiş̧ir. Çalışma yarı deneysel olarak tasarlanmıştır. Çalışmanın veri toplama araçları, matematik ders öğretmenlerinin uyguladığı yazılı sınav sonuçları, araştırmacının hazırladığı başarı testleri ve araştırmacının hazırladığı açık uçlu sorulardan oluşan ünite değerlendirme sınavlarından oluşmaktadır. Uygulamadan elde edilen verilerin analizi ise SPSS 15 istatistik programından yararlanarak yapılmıştır. Sonuç olarak, uygulamanın ilk döneminin sonunda ebeveyn desteği alan öğrencilerle ebeveyn desteği almayan öğrencilerin başarı durumları arasında istatistiksel olarak anlamlı bir fark görülmezken ikinci dönemin sonunda ebeveyn desteği alan öğrencilerle ebeveyn desteği almayan öğrencilerin başarı durumları arasında istatistiksel olarak anlamlı bir fark olduğu tespit edilmiştir. Bu durum bu tür bir uygulamada çalışmanın süresinin önemini düşündürmüştür.

Anahtar Sözcükler: Matematik eğitimi, ortaokul, ebeveyn desteği, akademik başarı.

\begin{abstract}
It is now supported by research that parental support is an issue that should be taken into consideration in mathematics education as well as education in general. However, there is limited research on how this support should be. Researches are generally correlational studies, and a few studies related to implementation are encountered. In this regard, this study aims to examine application-supported academic success. In this line, the purpose of this study is to identify to what extent parental support affects middle school students' mathematics achievement. With this aim, a group of sixth-grade students and their parents who were willing to participate in the study and a group of 6th-grade students without parental involvement were selected as the sample for the study. The application for the study was carried out for two weeks in two terms. The study was designed as a quasiexperimental study. The instruments of the study were written exams that were prepared by the mathematics class teachers, achievement tests and unit evaluation exams which were prepared by the researchers. The data obtained from the study were analyzed through the SPSS 15 statistics program. As a result, while there was no statistically significant difference between the students who received parental support and those who did not receive parental support at the end of the first semester of application, there was a statistically significant difference between the students who received parental support and those who did not receive parental support at the end of the second semester.
\end{abstract}

Keywords: Mathematics instruction, middle school, parent support, student achievement 


\section{Giriş}

Günümüzde gerek ülkemiz eğitim sisteminde, gerekse uluslararası eğitim sistemlerinde ebeveyn desteğinin eğitim öğretim sürecinin önemli bir parçası olduğu görülmektedir. OECD (2010) raporunda da ifade edildiği gibi eğitim ebeveynlerin, öğretmenlerin, okulların ve çeşitli enstitülerin sorumluluklarını paylaşmak durumunda kaldığı paylaşımlı bir olgu ve süreçtir (Gurria, 2010). Yine Guria (2010) OECD raporunda, PISA sonuçlarının ebeveyn desteğinin çocukların okul yıllarındaki ve daha ötesindeki başarılarında öncelikli bir faktör olduğunu belirtmiştir. Cotton ve Wikelund (1989) ebeveyn desteğini, eğitimde farklı katılım formlarında gerçekleşen bir durum olarak ifade etmişlerdir. Şöyle ki; ebeveynler çocuklarının eğitimine okul işlevlerine katılarak ve ihtiyaçlarına cevap vererek katılabilirler. Yine ebeveynler çocuklarının eğitimlerine okul görevlerine dahil olarak katılabilirler ki bu da ödev kontrolü, evde ders desteği, evde çalışma ortamı ve zamanı sağlamak gibi durumlardır. Ayrıca ebeveynler, okul içinde de yardımcı olabilirler; sınıftaki okul aktivitelerinde ve işlerinde gönüllü olabilirler, karar vermede, planlamada, gelişmede, ve toplumun tüm çocukları için eğitim sağlamada aktif bir rol üstlenebilirler. Ulusal ve uluslararası alan-yazın incelendiğinde, ebeveyn desteğinin daha çok ilk bahsedilen genel anlamdaki kısmı ile ilgili çalışmalara rastlanmış olup öğretim desteği anlamında daha az sayıda çalışmaya rastlanmıştır (Civil, Bratton ve Quintos, 2005; Civil, 2001; Civil, 1998).

Alanyazın incelendiğinde, ebeveyn desteğinin çeşitli aktivite ve bağlantıları içererek pek çok yönden gerçekleştirilebildiğine dikkat çekilmiştir (Epstein ve Sheldon, 2005). Bu doğrultuda da ebeveyn desteği olgusunun kategorileştirilmesi yoluna gidilmiştir. Ebeveyn desteğini Epstein (1995) altı tip olacak şekilde sınıflandırmıştır. Bunlar; ebeveynlik, iletişim kurma, gönüllülük, evde öğrenme, karar verme ve toplumla işbirliğidir.

Matematik eğitimi bağlamında ise Civil (1998, 2001, 2003) yapmış olduğu çalışmalarla matematik eğitiminde ebeveyn katılımının önemine dikkat çekmiştir. Civil, Bratton ve Quintos (2005) ebeveynleri entelektüel kaynaklar olarak düşünmüşlerdir. Bu noktada da ebeveyn rollerini şu kategorilere ayırmışlardır:

1. Ebeveynler olarak ebeveynler

2. Öğrenenler olarak ebeveynler

3. Öğretmenler olarak ebeveynler

4. Liderler olarak ebeveynler

Yine Civil, Bratton ve Quintos (2004) yürütmüş oldukları projelerinde ebeveynler için çeşitli amaçlı seminerler düzenlediklerini ifade etmişlerdir. Bunların sonucunda da ebeveynlerin bilgilenmesi ve bilinçlenmesinin çocuklarının okul başarısına olumlu yönde katkı sağladığı sonucuna varmışlardır. Bununla birlikte, ebeveynlerin kendi gelişimleri de çalışmaların dikkat çeken diğer bir yönüdür.

Çalışmaya teorik açıdan bakıldığında da Ernest (1996) öğrenme teorilerinden olan sosyal yapısalcılık kuramına göre bireyin sosyal ortamdan ayrı düşünülemeyecek bir özne olduğunu ifade eder. Bireyler, kendi bireysel süreçleri olduğu kadar birbirleriyle olan etkileşimleri vasıtasıyla da öğrenirler. Dolayısıyla, ögrenmede tamamen izole edilmiş bir birey zihninden bahseden metafor yoktur. Yıldırım (2010)'ın ifade ettiği sosyal destek çemberinde, çocuğun sosyal çevresinde birincil destek kaynağı olarak aile yani anne ve baba ifade edilmiştir. Öncelikli olarak ebeveynlerin yer aldığ bu sosyal destek çemberine göre çocukların sosyal yapısalcığa dayalı öğrenmelerinde ebeveynin rolü gayet açıktır.

Ancak ebeveynlerin bu rolü gerçekleştirmelerinde sahip oldukları farkındalıklar da önem arz etmektedir. Bu doğrultuda, bazı araştırmalar ebeveynlerin çocuklarına öğretimsel anlamda bireysel olarak çocuklarına yardım etmek için farkındalıkları olduğunu ortaya koymuştur. Örneğin, ebeveynlerin çocuklarının eğitimine neden katıldıkları ile ilgili Hoover-Dempsey ve Sandler (1997) bir araştırma yapmış olup bu araştırmada ebeveynlerin katılım kararlarındaki üç temel yapıya işaret edilmiştir. Bunlar; ebeveynlerin çocuklarının eğitimi ile ilgili nelerin önemli gerekli olduğu ve nelere izin verebileceklerine dair inançları, çocuklarının eğitimsel çıktılarına pozitif etki yaratması bakımından öz yeterlilik hisleri, ebeveynler için genel davetler, istekler ve firsatlardır. Çalışmada, ebeveynlerin öz yeterlilik hisleri doğrultusunda çocuklarının okul başarılarının da yükseldiği ifade edilmiştir. 
Çocuklar dünyaya gelişlerinden itibaren ilk olarak aile ortamında öğrenmeye başlarlar. Biyolojik, bilişsel ve sosyal gelişimlerinin etkin bir biçimde gerçekleştiği bu aile ortamı günümüz şartlarının da etkisi ile donanımlı olmaya ihtiyaç duymaktadır. Bu noktada ailelerin uzmanlarca bilgi edinebilecekleri programların düzenlenmesi günümüz toplumunda önemli bir ihtiyaç haline gelmiştir. $\mathrm{Bu}$ ihtiyaçları gidermek üzere ebeveynlerin eğitimi için aile eğitim programları düzenlenmektedir. $\mathrm{Bu}$ programlarda aileye çocuğunu yetiştirmek için ihtiyaç duyacağı bilişsel, duyuşsal ve sosyal bilgiler sunulmaktadır (Şahin ve Özbey, 2007).

Şu ana kadar ülkemizde, "eğitimde ebeveyn" teması üzerine yapılan çalışmaların genelde ilişkisel (korelasyon) çalışmalar olduğu, ebeveynlerin demografik özellikleri ile öğrenci başarısının ilişkisi gibi çalışmaların yapıldı̆̆ı, öğrencilerin öğrenmelerine yardım edebilecek "Evdeki öğretmen/öğretici: ebeveynler" teması üzerine deneysel çalışmalara yer verilmediği gözlenmiştir. Yani doğrudan ebeveyne öğreticilik ya da rehberlik misyonunun yüklendiği bir çalışmaya rastlanılamamıştır. Yurt dışı literatürde ise, ortaokul düzeyinde yapılması planlanan bu çalışmanın muadili sayılamayacak fakat bazı benzerlikler gösteren az sayıda çalışmaya rastlanılmıştır (Bernier, Civil, ve Quintos, 2003; Bratton, Civil ve Quintos, 2005; Civil, 2006; Civil, 2001).

Anderson (1997) sosyal yapısalcılığın ebeveynlerin çocukları etkileşimleri sonucu aktivite belirlemeleri ve yürütmelerini gerektirdiğini ifade etmiştir. Bu noktada literatür ebeveynlerin çocuklarının matematik yaşamına dahil olmalarının; çocuklarda gerek bilişsel (Şişman, 2002; Yenilmez, 2006) ve gerekse duyuşsal olumlu gelişmelere yol açabileceğini (Yenilmez ve Özabac1, 2003), öğrencilerin kaygılarını giderebileceğini (Alkan, 2011), çocuklarında matematik dersine tutum ve başarılarını doğrudan etkileyeceğini (Alkan, 2011), öğrencilerin matematiği içselleştirmelerinde çok önemli bir etken olduğunu (Mahdi, 2010), ev ve okul arasındaki kopukluğu giderebileceğini (Civil, 1998) ortaya koymuştur. Benzer şekilde Yenilmez, Özer ve Yıldız (2006) ebeveynlerin çocuklarının matematik yaşamına dahil olarak onların matematiğe karşı gerek bilişsel gerekse duyuşsal olumlu gelişmeler göstermelerinde rehber olmaları gerektiğini, bunun da ev ödevlerine yardımcı olmak, günlük yaşam matematiğine işaret etmek şeklinde olabileceğini ifade etmişlerdir. Alkan (2011) öğrencilerin matematik kaygılarının nedenlerinden biri olarak ebeveyn faktörünü göstermiştir. Bu kaygının oluşma nedenleri arasında ise ailelerin matematik bilgilerinin yetersiz olması ve bundan ötürü çocuklarına destek olamamaları yer almaktadır (Alkan, 2011). Bu çalışmanın sonuçlarına göre, ailelerin matematik bilgisi ve matematik dersine olan tutumu, çocukların da matematik dersine karşı tutum ve başarılarını doğrudan etkilediği ortaya çıkmıştır. Dolayısıyla, öğrencinin matematik başarısında ebeveyn desteği bir kez daha vurgulanmıştır (Alkan, 2011). Bu durum öğretmen-öğrenci-ebeveyn etkileşimini gerekli kılmaktadır. Literatür bulguları, eğitim-öğretimin doğası ve sosyal yapısalcılık kuramı gereği çocukların ve öğretmenlerin çabasının yanı sıra ebeveyn etmeninin de etkin matematik öğretimi için göz ardı edilmemesi gereken bir konu olduğunu göstermektedir. Okulda öğretmen rehberliğinde gerçekleşen eğitim-öğretim süreci okul dışında da ebeveynlerin etkin rehberliği ile desteklendiğinde çocukların daha yüksek performans göstermeleri beklenmektedir. Ebeveynlerin matematik dersi açısından etkin rehberliği için çocuklarının dersleri paralelinde eğitim görmeleri çocukların matematik bilgi ve beceri edinimlerine önemli ölçüde katkı sağlayacağı düşünülmektedir. Ayrıca bu etkinin duyuşsal boyutlarının da olacağı göz ardı edilmemelidir. Halat ve Kay (2009)'ın yaptıkları çalışmanın bulgularına dayanarak eğitim programları ve çeşitli seminerler vasıtasıyla, ebeveyn-öğretmen-idareci etkileşiminin arttırılarak daha etkileşimli ve donanımlı bir eğitim öğretim ortamı yaratmayı önermiş, bu durumun öğrencilerin matematik başarılarının arttıılması hedefinin bir parçası olduğunu belirtmişlerdir (Halat ve Kay, 2009). Öğrencilerin matematik öğrenmelerine ebeveynlerin katılımının son birkaç yıl içerisinde arttı̆̆ araştırmalarda ortaya konmuştur (Mahdi, 2010).

Ebeveynlerin matematik eğitimine olan katkısına dair olan alan yazın incelendiğinde yapılan çalışmaların en çok okul öncesi dönem çocukları üzerinde yapıldığı görülmüştür. Durum tespiti çalışmalarında ebeveynlerin yarıya yakının matematik içeriği hakkında kısmi bilgiye sahip olduğu, ebeveynlerin önemli bölümünün okul dışında çocukları ile matematik aktivitesi yapmadıkları, ebeveynlerin okul dışı matematik öğrenme ve pratik yapmanın matematik gelişimi için önemine inandıkları ortaya çıkmışken (Kesicioğlu ve Alisinanoğlu, 2013) ebeveynler entelektüel kaynak olarak düşünüldüğünde, ebeveynler okul içi ve okul dışı matematik öğrenme hakkında öğretmenlerle iletişim ve etkileşim halinde olduğu müddetçe öğretmenlerin ebeveynler ile olan iletişim ve etkileşim çıktıları 
çocukların matematik öğrenmeleri ve matematik eğitimine katkıda bulunacağı sonucuna varan çalışmalara da rastlanmıştır (Karslı ve Snider 2015). İlköğretim düzeyinde ise ebeveynlerin çocuklarına matematik öğrenme noktasında destek olup olmadıkları noktasında yapılan araştırmalarda, ebeveynlerin matematik eğitimine katılımları yorumlandığında, sınıf içi etkinliklerde, sınav hazırlık aşamasında, sınıf dışı etkinliklerde, izleme noktasında genel başarısı pekiyi olan öğrencilerin ebeveynleri diğerlerine oranla daha fazla katılım gösterdikleri sonucuna varılırken (Yenilmez, 2006) ebeveynlerin çocuklarının matematik başarılarını, çocukların kaygı düzeylerini azaltarak da etkiledikleri, onların evdeki desteklerinin çocuklarının sözel problemlerdeki ve cebirsel akıl yürütmelerindeki başarılarını çocukların matematik kaygılarını azaltarak etkiledikleri şeklinde bulunmuştur (Roberts ve Wright, 2013). Öte yandan matematik dersinin ebeveynlerce zor bir ders olarak algılandığı, geçmiş yaşantılarında matematikte güçlükler yaşadıkları, ancak çocuklarına yardımcı olmak istedikleri ve yardımcı olurken de bu durumdan zevk aldıkları sonucuna varan çalışmalara da rastlanmıştır (Karaca ve Gür, 2004). Ebeveynlerin çocuklarına matematik dersinde destek olmaları için bilgi ve desteğe ihtiyaçları olduğuna, çocuklarına yardım etmek isteyen bu ebeveynlerin "nasıl" destek olacaklarını bilemedikleri sonucuna varılmıştır. Diğer taraftan araştırmacıların matematik dersi hakkında ebeveynlere çocukların gelişimi açısından notlar göndermeleri, ebeveynlerin çocuklarının dahil olduğu etkinlerden haberdar olmaları gerektiği, ebeveynlerin okul içi ve dışı matematik etkinliklerine katılmaları gerektiği, gerektiğinde bunun için ebeveyn katılım programları organize edilebileceği konuları önerilmiştir (Karaca ve Gür, 2004). Uluslararası alan yazında ise Civil (2001) "Ebeveynler için Matematik" adlı seminerler içeren proje çalışmaları sonucunda, ebeveynlerin bir yandan çocuklarına yardımcı olmak için matematik öğrenirken bir yandan da kendilerini geliştirmeye odaklanmaya başladıklarını gözlemlediklerini, bu durumun onların matematik konuları hakkındaki fikirlerini daha rahatça ifade edip paylaşım yapmalarını kolaylaştırdığını gözlemlemiş̧lerdir ve bu doğrultuda matematiğin ebeveynler için bir ihtiyaç olduğu bulgularından yararlanarak "matematik forumları" tasarlamışlardır (Civil, Bratton ve Quintos, 2004).

Alan-yazın incelemesi sonucunda, ebeveyn desteği gerek ulusal gerekse uluslararası matematik eğitiminde ele alınan bir konu haline gelmiştir. Bu konuda yapılan araştırmalar ebeveynlerin çocuklarına destek olmak istediklerini, ancak destek olabilecek yeterli bilgi ve beceriye sahip olmadikları yönündedir. Ayrıca, ebeveynlerin katılmak istedikleri seminer ve organizasyonlara bu çalışmalar da dikkat çekilmiştir. Bu çalışmayla ülkemiz eğitim sisteminde matematik dersi başarısını arttırmaya yönelik ebeveyn desteğinin önemine dikkat çekilmek istenmiş ve gerçekleştirilen seminerlerle de ebeveynlerin çocuklarının matematik eğitimine katkı sağlamaları amaçlanmıştır.

Ebeveynlerin farklı demografik özellikleri dikkate alındığında, ebeveynlerin matematik dersinde nasıl destek olabilecekleri sorusunu akla getirmektedir. İlk olarak ebeveynlerin her birinin farklı demografik özelliklere sahip olduğu bilincinden hareketle ebeveynleri tekrar bir öğrenci gibi eğitmek makul bir düşünce olmayacağından bu desteğin ebeveynlere tekrar sadece matematik konuları hakkında bilgi vermek yerine bunun yanında onlara "evdeki destek" ve "rehber" görevi yükleme ile sağlanmasının makul olabileceği fikri doğmuştur. Dolayısıyla sadece öğretme değil, destek olma rolü de tüm ebeveynler için gerçekleştirilebilir bir olgudur. Burada temel felsefe, araştırmac1-ebeveyn işbirliği halinde, araştırmacı tarafından hazırlanan konu açıklamalarının ve alıştırmaların ebeveynler ile bu süreçte paylaşmasıdır. Bu süreçte, ebeveynlere konular hakkında genel bir bilgi vermenin yanında ihtiyaç halinde, alıştırmaları kullanabilme becerisi kazandırılmaya çalışılmıştır. Yapılan çalışmalar da göstermektedir ki, ebeveynlerin öğrenim seviyeleri ile çocuklarına matematik dersinde destek olabilme düşünceleri açısından anlamlı bir fark gözlemlenmemiştir (Halat ve Kay, 2009). Bu durum heterojen yapıya sahip olması muhtemel ebeveynlere rehberlik rolünü verecek çalışmanın uygulanabilirliğinin göstergelerinden biridir.

Alan-yazın doğrultusunda, gerçekleştirilmiş olan bu çalışmanın problemi; "Ebeveyn desteği alan beşinci ve altıncı sınıf öğrencilerinin matematik ders başarısı ve matematik dersine yönelik tutumları ebeveyn desteği almayan beş ve altıncı sınıf öğrencilerinin matematik ders başarısı ve matematik dersine yönelik tutumlarından farklılık göstermekte midir?" şeklinde belirlenmiştir. Çalışmanın alt problemi olarak da "Ebeveyn desteği alan öğrencilerin matematik ders başarıları, ebeveyn desteği almadan çalışan öğrencilerin matematik ders başarılarından ne derece farklılık göstermektedir?" şeklinde belirlenmiştir. Çalışmanın temel amacı ise ortaokul düzeyinde öğrenim gören öğrencilerin ebeveynlerine, kendi çocuklarına ihtiyaçları halinde yardım edebilecekleri matematiksel 
bilgiler içeren etkinlikler sunup bu yolla matematik eğitimi gerçekleştirerek öğrencilerin matematik ders başarı durumlarındaki değişimi gözlemlemektir. Bu doğrultuda "araştırmaya katılan deney ve kontrol grubu öğrencileri arasında matematik başarıları açısından anlamlı bir fark olup olmadığını belirlemek" biçiminde bir alt amaç belirlenmiştir.

\section{Yöntem}

\section{Araştırmanın Tasarlanması}

$\mathrm{Bu}$ araştırma üç aşamada gerçekleştirilmiştir. İlk olarak ebeveynlere çalışmayı anlatmak ve bilgilendirmek için ebeveyn seminerleri düzenlenmiştir. Bu seminerler sonrasında gönüllülük esaslı ebeveyn seçimi gerçekleştirilmiştir. İkinci aşamada, ebeveynlere yönelik matematik seminerleri düzenlenmiştir. Yine bu süreçte öğrencilere ünite değerlendirme sınavları yapılmıştır. Son olarak da dönem sonunda, öğrencilere çoktan seçmeli sorulardan oluşan başarı testi uygulanmıştır.

\section{Araştırma Yöntemi}

Araştırma, nicel araştırma olarak tasarlanmıştır. Çalışmada, deney-kontrol gruplu yarı deneysel desen kullanılmıştır. Yarı deneysel desende deney grubu ve kontrol grubu rastgele atama yapılmaksızın seçilir ve deneysel işlem sadece deney grubuna uygulanmıştır (Creswell, 2012). Deney grubu gönüllülük esasına dayalı olarak matematik farkındalık seminerine katılmak isteyen ebeveynlerin öğrencilerinden oluşmuştur. Kontrol grubu ise ebeveynleri seminere katılmayan öğrencilerden oluşmuştur. Dönem ortalarında her iki gruba ünite değerlendirme sınavları uygulanmıştır. Ayrıca, matematik ders öğretmenlerinin uyguladığ matematik yazılı sınavlarından yararlanılmıştır. Son olarak dönem sonlarında her iki gruba da akademik başarı testleri yapılmıştır. Öğrencilerin matematik dersi akademik başarı durumlarındaki değişimin incelenmesinde kontrol gruplu son test deseni kullanılmıştır.

\section{Katılımcilar}

Çalışma grubu ve yöntemi, ebeveyn desteği ve matematik eğitiminde ebeveyn desteği ile ilgili yapılan çalışmalardan yararlanılarak belirlenmiştir. Araştırmanın çalışma grubunu bir eğitim-öğretim döneminde üç ortaokulda öğrenim gören 8 beşinci sınıf öğrencisi ve bunların ebeveynleri deney grubu olarak; bu öğrencilerle yaklaşık başarı düzeyine sahip ebeveyn desteği almayan sekiz beşinci sınıf öğrencisi de kontrol grubu olarak oluşturulmuştur. Takip eden eğitim öğretim döneminde de bu örnekleme ek olarak bir okul ile toplam dört ortaokuldan deney grubu olarak 13 altıncı sınıf öğrencisi ve bunların ebeveynleri ile yaklaşık aynı başarı düzeyine sahip ebeveyn desteği almayan 13 altıncı sınıf öğrencisi kontrol grubu olarak oluşturulmuştur. Ancak ilk dönem çalışmaya katılan bir ebeveyn ikinci dönem seminerlere katılamadığı için toplam 12 deney grubu öğrencisi ve ebeveyni çalışmaya dahil edilmiştir.

Çalışmanın ikinci döneminde üç okulda yedi hafta ve ilk dönemde dört okulda yedi hafta çalışma yapılmıştır. Bu haftalar boyunca, haftada bir kez iki ders saati boyunca ebeveynlere matematik seminerleri düzenlenmiştir. Bu seminerlerde, ebeveynlere çocuklarının okulda gördükleri matematik konuları, ulusal matematik öğretim programı esas alınarak onların bilgilenebileceği düzeyde paylaşılmıştır. Burada amaç, ebeveynlerin çocuklarının okulda matematik dersinde gördükleri konular hakkında bilgilenmelerini sağlayarak evde ihtiyaç duyulduğunda çocuklarına destek olabilmelerini sağlamaktır. Süreç içerisinde, veri toplama amacıyla öğrencilerle de etkinlikler gerçekleştirilmiştir. Her iki çalışma döneminde de hem ebeveyn desteği alan hem de bireysel çalışan öğrencilere dönem sonunda son test olacak şekilde çoktan seçmeli sorulardan oluşan başarı testleri uygulanmıştır. Birinci uygulama döneminde, ayrıca bir adet açık uçlu sorulardan oluşan ünite değerlendirme sınavı yapılmıştır. Aynı şekilde, ikinci uygulama döneminde de öğrencilere açık uçlu sorulardan oluşan iki adet ünite değerlendirme sınavı uygulanmıştır.

\section{Veri Toplama Araçları}

i. Ö̆̆renci Başarı Testleri: Öğrencilere dönem sonlarında uygulanan testlerdir. Testler, müfredata uygun olarak uzmanlarla beraber hazırlanmıştır. Başarı testleriyle öğrencilerin uygulama sonrası arasındaki farkın daha net ortaya konulması amaçlanmıştır. 
ii. Ünite Değerlendirme Sınavları: Öğrencilere dönem ortalarında uygulanan açık uçlu sınavlardır. Sınavlar, müfredata uygun olarak uzmanlarla beraber hazırlanmıştır. Ünite değerlendirme sınavlarıyla öğrencilerin uygulama sonrası arasındaki farkın daha net ortaya konulması amaçlanmıştır.

iii. Yazılı Sınavlar: Öğrencilere matematik ders öğretmenlerinin dönem ortalarında uyguladığı sinavlardır. Yazılı sınavlarıyla öğrencilerin uygulama sonrası arasındaki farkın daha net ortaya konulması amaçlanmıştır.

\section{Verilerin Analizi}

Veriler, SPSS 15 istatistik programı kullanılarak analiz edilmiştir. Analizde, bağımsız örneklem t-testine ve betimleyici istatistik verilerine bakılmış ve sonuçlar yorumlanmıştır.

\section{Bulgular}

Çalışmanın ikinci döneminde, DGR(6) ve EBV(6 ) hariç diğer öğrenciler ve deney grubu öğrencilerinin ebeveynleri çalışmaya devam etmişlerdir. Bu örnekleme ek olarak deney grubundan beş öğrenci ve ebeveyni, kontrol grubundan da beş öğrenci daha çalışmaya katılmıştır. Elde edilen veriler, SPSS 15 istatistik programı kullanılarak analiz edilmiştir. Analiz sonuçları, kontrol ve deney grubu öğrencilerinin son test başarı karşılaştırmaları ve genel başarı karşılaştırmaları şeklinde aşağıda tablo halinde verilmiştir. Öğrencilerin 1. dönem son test ve genel başarılarına dair bulgular Tablo 1 ve Tablo 2'de; 2. dönem son test ve genel başarılarına dair bulgular Tablo 3 ve Tablo 4 'te verilmiştir.

Tablo 1.

Dönem Deney ve Kontrol Grubu Öğrencilerinin Son Test Başarıları

\begin{tabular}{lcclccc}
\hline Gruplar & N & $\boldsymbol{M}$ & $\mathbf{s}$ & sd & t & $\boldsymbol{p}$ \\
\hline DGR & 8 & 63.12 & 9.23 & 14 & 3.32 & \\
\cline { 1 - 4 } & 8 & 46.87 & 10.33 & & 3.32 & 0.005 \\
\hline
\end{tabular}

Öğrencilerin son test başarı puanlarına göre, matematik dersindeki akademik başarıları ebeveyn desteği alıp almamaya göre anlamlı bir farkl11ık göstermektedir $t(16)=3.31, p=.005$. Deney grubunun matematik dersi akademik başarısı $(M=63.12 ; \mathrm{s}=9.23)$, kontrol grubunun matematik dersi akademik başarısına $(M=46.87, \mathrm{~s}=10.32)$ göre anlamlı derecede yüksektir. Cohen $\mathrm{d}=1.66$ yüksek düzeyde etki büyüklüğüne sahiptir. Bu bulgu, beşinci sınıf öğrencilerinde ebeveyn desteği alma ile almama arasında anlamlı bir farklılık olduğu şeklinde yorumlanabilir.

Tablo 2.

Dönem Deney ve Kontrol Grubu Öğrencilerinin Başarıları

\begin{tabular}{llccccc}
\hline Gruplar & N & $\boldsymbol{M}$ & s & sd & t & $\boldsymbol{p}$ \\
\hline DGR & 8 & 65.25 & 13.39 & 14 & 1.93 & .074 \\
\hline KGR & 8 & 52.25 & 13.58 & & 1.93 & .074 \\
\hline
\end{tabular}

Öğrencilerin genel başarı puanlarına göre, matematik dersindeki genel akademik başarıları ebeveyn desteği alıp almamaya göre anlamlı bir farkl1lık göstermemektedir $\mathrm{t}(16)=1.92, p=0.074>.05$. Ancak, deney grubunun matematik dersi akademik başarısı $(M=65.25)$, kontrol grubunun matematik dersi akademik başarısına $(M=52.25)$ göre anlamlı derecede yüksektir. Cohen $\mathrm{d}=0.96$ yüksek düzeyde etki büyüklüğüne sahiptir. Bu bulgu, beşinci sınıf öğrencilerinde ebeveyn desteği alma ile almama arasında istatistiki olarak anlamlı bir ilişki olmadığı şeklinde yorumlanabilir.

Tablo 3 .

İkinci Dönem Deney ve Kontrol Grubu Öğrencilerinin Son Test Başarıları

\begin{tabular}{lcccccc}
\hline Gruplar & N & $\boldsymbol{M}$ & $\mathbf{s}$ & $\mathbf{s d}$ & $\mathbf{t}$ & $\boldsymbol{p}$ \\
\hline DGR & 11 & 64.54 & 20.18 & 22 & 1.90 & .07 \\
\hline KGR & 13 & 51.15 & 14.16 & & 1.84 & .08 \\
\hline
\end{tabular}

Öğrencilerin son test başarı puanlarına göre, matematik dersindeki akademik başarıları ebeveyn desteği alıp almamaya göre anlamlı bir farkl1lık göstermemektedir $\mathrm{t}(24)=1.90 ; 1.84, p>.05$. Ancak; deney grubunun matematik dersi akademik başarısı $(M=64.54)$, kontrol grubunun matematik dersi akademik başarısına $(M=51.15)$ göre anlamlı derecede yüksektir. Cohen $\mathrm{d}=0.77$ orta düzeyde etki 
büyüklüğ̈̈ne sahiptir. Bu bulgu, 6.sınıf öğrencilerinde ebeveyn desteği alma ile almama arasında istatistiki olarak anlamlı bir ilişki olmadığı sonucu şeklinde yorumlanabilir.

Tablo 4.

İkinci Dönem Deney ve Kontrol Grubu Öğrencilerinin Matematik Ders Başarıları

\begin{tabular}{lcccccc}
\hline Gruplar & $\mathbf{N}$ & $\boldsymbol{M}$ & $\mathbf{s}$ & $\mathbf{s d}$ & $\mathbf{t}$ & $\boldsymbol{p}$ \\
\hline DGR & 12 & 65.00 & 18.94 & 23 & 2.03 & 0.05 \\
\cline { 1 - 5 } KGR & 13 & 49.69 & 18.72 & & 2.02 & \\
\hline
\end{tabular}

Öğrencilerin genel başarı puanlarına göre, matematik dersindeki akademik başarıları ebeveyn desteği alıp almamaya göre $\mathrm{t}(25)=2.03,2.02, p=.05$ düzeyinde anlamlı bir farklılık göstermektedir. Deney grubunun matematik dersi akademik başarısı $(M=65)$, kontrol grubunun matematik dersi akademik başarısına $(M=49.69)$ göre daha olumludur. Cohen $\mathrm{d}=0.81$ yüksek düzeyde etki büyüklüğüne sahiptir Bu bulgu, 6.sınıf öğrencilerinde ebeveyn desteği alma ile almama arasında anlamlı bir ilişki olduğu sonucu şeklinde yorumlanabilir.

\section{Tartışma, Sonuç ve Öneriler}

Araştırmacı ve ders öğretmenleri tarafından uygulanan tüm sınavların ortalamaları dikkate alındığında, deney ve kontrol grubu öğrencilerinin matematik ders başarılarında istatistiksel olarak anlamlı bir fark bulunmuştur. Deney grubunun matematik dersi akademik başarısı kontrol grubunun matematik dersi akademik başarısına göre daha olumludur. Bu bulgu, 6.sınıf öğrencilerinde ebeveyn desteği alma ile almama arasında anlamlı bir ilişkinin olduğu şeklinde yorumlanmıştır.

"Ebeveyn desteğinin 6. sınıf öğrencilerinin matematik başarısına ne derece etki ettiğgi” sorusuna yönelik yürütülen bu çalışmada, ebeveyn desteği alan öğrencilerin matematik başarılarının ebeveynlerinin matematik seminerlerine düzenli katılmaları ile doğru orantılı olarak kontrol grubu öğrencilerinin matematik ders başarılarına göre önemli derecede artış gösterdiği sonucuna varılmıştır. Kuramsal çerçevede de belirtildiği gibi bu projelerde ve bu çalışmada, çağımızın matematik öğrenme kuramları olan matematiği kendi içerisinde bir bilimsel kültür olarak ele alan yapısalcılık ve sosyal etkileşimden kaynaklanan etkin öğrenme kuramı olarak sosyokültürel yaklaşımın bir bileşimi olan sosyal yapısalcılık benimsenmiştir. Bu kuram ve benzer yapısalcı kuramlar esas alınarak yapılan çalışmalar sonucunda; ebeveyn desteğinin; 5. ve 6. sinıf düzeyinde öğrencilerin matematik ders başarılarına olumlu yönde etki ettiği görülmüştür. Karslı ve Snider (2015)'in yaptıkları çalışmada ebeveynler entelektüel kaynak olarak düşünülmüş, ebeveynler okul içi ve okul dışı matematik öğrenme hakkında öğretmenlerle iletişim ve etkileşim halinde olduğu müddetçe öğretmenlerin ebeveynler ile olan iletişim ve etkileşim çıktıları çocukların matematik öğrenmeleri ve matematik eğitimine katkıda bulunacağı sonucuna varılmıştır. Bu bulgulara benzer olarak ebeveyn desteğinin öğrencilerin matematik başarılarıyla direkt doğru orantılı olduğu sonucuna varılmıştır (Vukovic, Roberts ve Wright, 2013). Ebeveynlerle matematik kulüpleri gerçekleştirerek ve bu kulüpler kapsamında ebeveynlerin evde çocuklarıyla paylaşımlar gerçekleştirmeleri sağlanarak çocukların matematik başarısında olumlu yönde bir ilerleme gözlemlenmiştir (Civil, 1998; McKey,1985; Muir, 2012; Steinberg, Lamborn, Dornbusch ve Darling, 1992). Öte yandan, velilerin matematiğe karşı ilgi düzeyi arttıkça katkısının da arttığı, matematik bilgi düzeyi açısından orta ve yüksek matematik bilgi düzeyine sahip ebeveynlerin düşük matematik bilgi düzeyine sahip ebeveynlere göre daha fazla katkı sağladıkları (Yenilmez, Özer ve Yıldız, 2006) görülürken SBS puanları ve veli ilgisi ile ilgili yapılan bir başka araştırmada da eğitime katılım ve okul tutumları yüksek olan velilerin öğrenim gören çocuklarının SBS puanlarının yüksek olduğu, eğitime katılım ve okul tutumları düşük olan velilerin çocuklarının SBS puanlarının düşük olduğu bulgusuna ulaştıkları görülmüştür (İpek, 2011). Bu çalışma ile ebeveyn desteği alan öğrencilerin, destek almayan öğrencilere oranla ebeveynlerinin seminerlere düzenli katılımları süresince, daha başarılı oldukları ortaya konmuştur. Çalışmanın örneklem daha geniş tutulduğunda, ebeveynler her hafta düzenli olarak seminerlere katıldıklarında ve çalışma süresi daha uzun olduğunda çok daha iyi sonuç vereceği düşünülmektedir. Ayrıca, ebeveynlerin görüşleri doğrultusunda çalışmaya çocukların da katılması ebeveyn-çocuk iletişimi ve etkileşimi açısından faydalı olarak matematik başarısında daha etkili olacağı tartışılmıştır. Bu veri ve önerilere benzer olarak matematik alanyazınında teknik matematik bilgisi gerektirmeyen ebeveyn katılımın çocuklarının matematikte istenen başarıya ulaşmaları için gerekli öğrenme ortamını evlerinde 
sağlayabilmeleri için değişik kültürel yollarla eğitim, kaynak ve destek almaları şeklinde tavsiyelere rastlanmıştır (Vukoviç, Roberts ve Wright 2013). 


\section{Kaynakça}

Alkan, V. (2011). Etkili matematik öğretiminin gerçekleştirilmesindeki engellerden biri: Kayg1 ve nedenleri. Pamukkale Üniversitesi Ë̆itim Fakültesi Dergisi, 29(1), 89-107.

Anderson, A. (1997). Families and mathematics: A study of parent-child interactions. Journal for Research in Mathematics Education, 28(4), 484-511.

Bratton, J., Civil, M., \& Quintos, B. (2005). Engaging with parents on a critical dialogue about mathematics education. Proceedings of the fourth congress of the european society for research in mathematics education.

http://www.mathematik.unidortmund.de/ erme/CERME4/CERME4_WG10.pdf\#page=60adre sinden 02.03.2020 tarihinde erişildi.

Bratton, J., Quintos, B., \& Civil, M. (2004). Collaboration between researchers and parents for the improvement of mathematics education. 1st Annual binational symposium of education researchers, Mexico City, Mexico. Erişim adresi: https://www.math.arizona.edu/ civil/BrattonQuintosCivil-MexicoSymp-04.pdf.

Civil, M. (2006). Working towards equity in mathematics education: A focus on learners, teachers, and parents. Proceedings of the Twenty Eighth Annual Meeting of the North American Chapter of the International Group for the Psychology of Mathematics Education, Mérida, Yucatán, Méksika.

Civil, M., Bratton, J., \& Quintos, B. (2005). Parents and Mathematics Education in a Latino Community: Redefining Parental Participation. Multicultural Education, 13(2), 60-64.

Civil, M., Quintos, B., \& Bernier, E. (2003). Parents as observers in the mathematics classroom: Establishing a dialogue between school and community. Annual conference of NCTM: Research Pre-session, San Antonio, USA, April. Erişim adresi: http://mathandparents.math.arizona.edu/papers/NCTM_2003_Parents.pdf.

Civil, M. (2001). Redefining parental involvement: Parents as learners of mathematics. NCTM research presession, FL, USA.

Civil, M. (1998). Bridging In-School Mathematics and Out-of-School Mathematics. Annual meeting of the american educational research association, CA, Amerika. Erişim adresi: https://files.eric.ed.gov/fulltext/ED425066.pdf

Cotton, K., \& Wikelund, K.R. (1989). Parent involvement in education. Erişim adresi: http://educationnorthwest.org/sites/default/files/parent-involvement-in-education.pdf

Creswell, J.W.(2012). Educational research: planning, conducting, and evaluating quantitative and qualitative research. (4. Bask1) Boston: Pearson Education.

Epstein, J. L. (1995). School/family/community partnerships: Caring for the children we share. Phi Delta Kappan, 76, 701-712.

Ernest, P. (1996). Varieties of constructivism: A framework for comparison. Leslie P. Steffe, Pearla Nesher, Paul Cobb, Gerald A. Goldin ve Brian Greer. (Ed.)Theories of mathematical learning içinde, (s.335-350).New York ve Londra: Routledge

Gurria, A. (2010). PISA 2009 Results: what students know and can do student performance in reading, mathematics and science. Erişim adresi: https://www.oecd.org/pisa/pisaproducts/48852548.pdf

Halat, E. Ve Kay, O. (2009). Yeni 2005 ilköğretim matematik öğretim programının veli görüşleri doğrultusunda değerlendirilmesi: Eğitim düzeyi. Erzincan Üniversitesi Eğitim Fakültesi Dergisi, 11(2), 133-150.

Hoover-Dempsey, K. V., \& Sandler, H. M. (1997). Why do parents become involved in their children's education?. Review of Educational Research, 67(1), 3-42.

İpek, C. (2011). Velilerin okul tutumu ve eğitime katılım düzeyleri ile aileye bağlı bazı faktörlerin ilköğretim öğrencilerinin seviye belirleme sınavları (sbs) üzerindeki etkisi. Pegem Eğitim ve Öğretim Dergisi, 1(2), 69-79.

Karsl1, E., \& Allexsaht-Snider, M. (2015). Video-cued parental dialogs: a promising venue for exploring early childhood mathematics. Eğitim ve Bilim, 40(179), 217-240.

Karaca, D., ve Gür, H. (2004). Köy ve şehir yerleşim yerlerindeki ailelerin matematik öğretimine katılımı. V. Ulusal fen bilimleri ve matematik eğitimi kongresi, http://www.fedu.metu.edu.tr/ufbmek-5/b_kitabi/b_kitabi.htm. 
Kesicioğlu, O. S., ve Alisinanoğlu, F. (2013). Okul öncesi dönem çocukların okul dışı (informal) matematik öğrenme süreçlerine ilişkin aile görüşleri. The Journal of Academic Social Science Studies, 6(7), 671-685.

Mahdi, O. (2010). A Qualitative investigation of home-school relationships and children's mathematics learning in-and out-of-school in Bahrain. Procedia-Social and Behavioral Sciences, 8, 427-438.

McKey, R. H. (1985). The Impact of Head Start on Children, Families and Communities. Final Report of the Head Start Evaluation, Synthesis and Utilization Project. Washington: DHHS

Muir, T. (2012). Numeracy at home: Involving parents in mathematics education. International Journal for Mathematics Teaching and Learning, 13(1), 1-13.Erişim adresi: http://www.cimt.org.uk/journal/index.htm

Sheldon, S. B., \& Epstein, J. L. (2005). Involvement counts: Family and community partnerships and mathematics achievement. The Journal of Educational Research, 98(4), 196-207.

Steinberg, L., Lamborn, S. D., Dornbusch, S. M., \& Darling, N. (1992). Impact of parenting practices on adolescent achievement: Authoritative parenting, school involvement, and encouragement to succeed. Child Development, 63(5), 1266-1281.

Şahin, F. T., \& Özbey, B. U. S. (2007). Aile eğitim programlarına niçin gereksinim duyulmuştur? Aile eğitim programları neden önemlidir?. Sosyal Politika Çalışmaları Dergisi, 3 (12), 7-12.

Şişman, M. (2013). Eğitimde mükemmellik arayışı, etkili okullar Ankara: Pegem A Yayınları.

Vukovic, R. K., Roberts, S. O., \& Green Wright, L. (2013). From parental involvement to children's mathematical performance: The role of mathematics anxiety. Early Education \& Development, 24(4), 446-467.

Yenilmez, K. (2006). İlköğretimde velilerin matematik eğitimine katkı düzeyleri. Abant İzzet Baysal Üniversitesi Eğitim Fakültesi Dergisi.6(1), 13-28.

Yenilmez, K., ve Özabacı, N. Ş. (2003). Yatılı öğretmen okulu öğrencilerinin matematik ile ilgili tutumları ve matematik kaygı düzeyleri arasındaki ilişki üzerine bir çalışma. Pamukkale Üniversitesi Ĕ̈itim Fakültesi Dergisi, 14(14), 132-146.

Yıldırım, İ. (2010). Anne baba desteği ve başarı: Anne babalar çocuklarına nasıl destek olabilirler. Ankara: Anı Yayıncilık. 


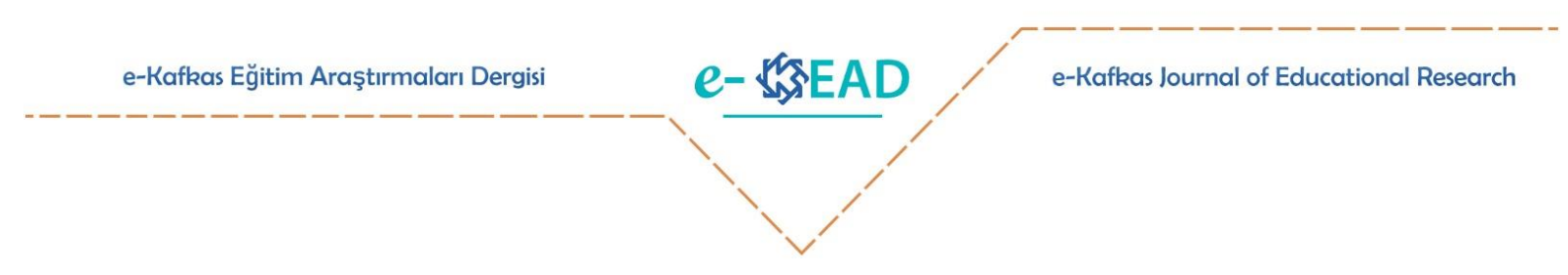

\section{An Investigation of Mathematics Achievements of Middle School Students in Terms of Parental Support}

\section{Zekiye Morkoyunlu Alper Cihan Konyalıŏlu}

To cite this article: Morkoyunlu, Z. ve Konyalığlu, A. C. (2020). Ortaokul öğrencilerinin matematik ders başarılarının ebeveyn desteği açısından incelenmesi. e- Kafkas Eğitim Araştırmaları Dergisi, 7, 16-27. doi: $10.30900 /$ kafkasegt. 680563

\section{Research Article}

Received: 27.01 .2020

\section{Introduction}

Today, parental support is seen as one of the important components of the instruction and education systems, both in Turkey and the world at large. Education is an activity in which parents, teachers, schools, and institutions share responsibilities. Additionally, PISA results show that parental support is a prominent factor in students' academic achievement during the school years and beyond (Gurria, 2002). Parental support occurs in different forms of participation in education (Cotton \& Wikelund, 1989). Parents can participate in their children's education by participating in school activities. Also, parents can participate in their children's education through their children's schoolwork, such as homework checking, supporting children at home, and providing children a study place and time at home. Additionally, parents can be helpful within the school, for example, volunteering for school activities and activities in the classroom; playing an active role in decision-making, planning, development; and helping to provide education for all children of society. In the literature, several studies were found related to the first part of parental support, but fewer studies were found in terms of teaching support.

In the context of mathematics education, Civil $(1998,2001,2003)$ emphasized the importance of parental participation in mathematics education with her several studies. Civil, Bratton, \& Quintos (2005) considered parents to be intellectual sources. At this point, they divide the parent roles into the following categories;

1. Parents as parents

2. Parents as learners

3. Parents as teachers

4. Parents as leaders

Again, Civil, Bratton \& Quintos (2004) stated that they have organized various seminars for parents in their projects. As a result, they have concluded that the knowledge and awareness of the parents contributed positively to the success of their children. However, the parents' own development is another remarkable aspect of the studies. The problem of this study is: "Do fifth and sixth-grade students receive parental support in their mathematics course success, and do parents' attitudes towards the mathematics course differ from the 5th and 6th-grade students' attitudes?" The question, "How does the mathematics achievement of students who receive parental support differ from that of students without parent support?" was identified as a sub-problem of the study. The main purpose of the study is to observe the changes in middle school students' mathematics achievement by presenting mathematical knowledge to their parents, therefore, they can help their children in case of need. In this context, a subobjective has been defined to determine whether there is a significant difference in terms of achievement 
in mathematics between the experimental and the control groups of students who participated in the research.

\section{Method}

The research was designed as a quantitative study. In this study, a quasi-experimental design with an experimental and a control group was used. The experimental group consisted of students and their parents who wanted to participate in mathematics awareness seminars on a voluntary basis. The control group consisted of students whose parents did not attend the seminar. Unit evaluation exams were applied to both groups at mid-terms. In addition, mathematics written exams applied by mathematics teachers were also used. Lastly, academic achievement tests were conducted in both groups at the end of the term. The design of the final test for the control group was used to examine the changes in the academic achievement level of students.

The study group and method were determined by using the findings of the studies on parent support in mathematics education. The study sample consisted of eight 5 th grade children and their parents as the experimental group and eight otherfifth grade children as the control group during the first semester of the school year. In the following semester, the sample consisted of 12 sixth grade children and their parents as the experimental group and 13 other sixth grade children as the control group.

The instruments were student achievement tests, unit evaluation exams, written exams. Data were analyzed using the SPSS 15 statistics program. In the analysis, an independent sample t-test and descriptive statistics were applied.

\section{Findings}

According to the students' final test achievement scores during the first term of the study, academic achievement in the mathematics course showed a significant difference compared to whether or not students received parental support $(\mathrm{t}(16)=3.31, \mathrm{p}=0.005<.05)$. On the other hand, the students' general academic achievement in mathematics did not show a significant difference according to whether or not they received parental support $(\mathrm{t}(16)=1.92, \mathrm{p}=0.074>.05)$.

According to the final test achievement scores of the students during the second term of the study, the academic achievement in the mathematics course did not show a significant difference compared to whether or not students received parent support $(\mathrm{t}(24)=1.90 ; 1,84, \mathrm{p}>.05)$. However, the academic achievement of the students in the mathematics course showed a significant difference at $t$ $(25)=2.03,2.02, \mathrm{p}=.05$, according to whether or not students received parental support.

\section{Discussion, Conclusion, and Recommendations}

In this study, it was concluded that the mathematics achievements of the students receiving parental support increased significantly in comparison with the mathematics achievements of the control group students in line with the regular participation of the parents in the mathematics seminars. In the study conducted by Karsl \& S Snider (2015), parents were considered an intellectual resource. It was concluded that the teachers' communication and interaction outcomes with parents contributed to mathematics learning and mathematics education as long as parents were in communication and interaction with teachers about the learning of mathematics in and out of school. Similar to these findings, it was concluded that parental support was directly proportional to the students' mathematics achievement (Vukovic, Roberts ve Wright, 2013). Positive movement in the mathematics achievement of children was achieved by organizing mathematics clubs with parents which enabled parents to share their knowledge and skills with their children at home (Civil, 1998, McKey,1985, Muir 2012; Steinberg, Lamborn, Dornbusch, ve Darling, 1992). Additionally, it was observed that the contribution of parents to mathematics increased as the parents' level of interest in mathematics increased, and, in terms of mathematics knowledge, parents with moderate and high levels of mathematics knowledge were found to contribute more than parents with low mathematics knowledge. (Yenilmez, Özer \& Y1ld1z, 2014). 